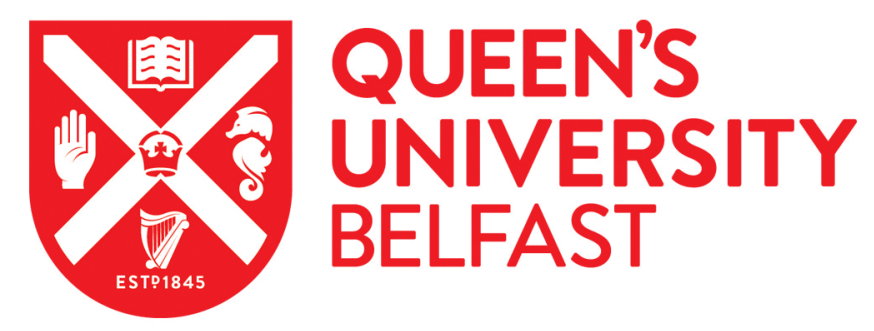

\title{
Modelling the correlation between processing parameters and properties of maraging steels using artificial neural network
}

Guo, Z., \& Sha, W. (2004). Modelling the correlation between processing parameters and properties of maraging steels using artificial neural network. Computational Materials Science, 29 (1)(1), 12-28.

https://doi.org/10.1016/S0927-0256(03)00092-2

Published in:

Computational Materials Science

Queen's University Belfast - Research Portal:

Link to publication record in Queen's University Belfast Research Portal

\section{General rights}

Copyright for the publications made accessible via the Queen's University Belfast Research Portal is retained by the author(s) and / or other copyright owners and it is a condition of accessing these publications that users recognise and abide by the legal requirements associated with these rights.

Take down policy

The Research Portal is Queen's institutional repository that provides access to Queen's research output. Every effort has been made to ensure that content in the Research Portal does not infringe any person's rights, or applicable UK laws. If you discover content in the Research Portal that you believe breaches copyright or violates any law, please contact openaccess@qub.ac.uk. 


\title{
Modelling the correlation between processing parameters and properties of maraging steels using artificial neural network
}

\author{
Z. Guo, W. Sha * \\ Metals Research Group, School of Civil Engineering, Queen's University of Belfast, Belfast BT9 5AG, UK
}

Received 8 May 2002; accepted 2 December 2002

\begin{abstract}
An artificial neural network (ANN) model is developed for the analysis and simulation of the correlation between the properties of maraging steels and composition, processing and working conditions. The input parameters of the model consist of alloy composition, processing parameters (including cold deformation degree, ageing temperature, and ageing time), and working temperature. The outputs of the ANN model include property parameters namely: ultimate tensile strength, yield strength, elongation, reduction in area, hardness, notched tensile strength, Charpy impact energy, fracture toughness, and martensitic transformation start temperature. Good performance of the ANN model is achieved. The model can be used to calculate properties of maraging steels as functions of alloy composition, processing parameters, and working condition. The combined influence of Co and Mo on the properties of maraging steels is simulated using the model. The results are in agreement with experimental data. Explanation of the calculated results from the metallurgical point of view is attempted. The model can be used as a guide for further alloy development.

(c) 2003 Elsevier B.V. All rights reserved.
\end{abstract}

Keywords: Artificial neural network; Precipitation hardening; Mechanical properties; Processing; Maraging steels

\section{Introduction}

Precipitation strengthening remains one of the most effective ways of producing ultrahigh-strength alloys. It is achieved by producing a particulate dispersion which acts as obstacles to dislocation movement through a second phase precipitation process. Over the past 40 years, a generic class of precipitation hardening $(\mathrm{PH})$ steels, maraging

\footnotetext{
${ }^{*}$ Corresponding author. Tel.: +44-28-9027-4017; fax: +4428-9066-3754.

E-mail address: w.sha@qub.ac.uk (W. Sha).
}

steels, has been developed, mainly for aircraft, aerospace, and tooling applications. Maraging refers to the ageing of martensite. The hardening is due to precipitation, usually of intermetallic compounds, during the ageing process [1-7].

Maraging steels, ${ }^{1}$ characterised by a large proportion of alloying elements, are expensive

\footnotetext{
${ }^{1}$ Maraging steels belong to the category of PH steels. They share many features with low carbon PH (stainless) steels. In the context of this paper, the term 'maraging steels' covers both maraging steels and the group of low carbon $\mathrm{PH}$ (stainless) steels unless particularly mentioned.
} 
materials compared with many other engineering alloys. The alloy development is significantly influenced by the availability and price of the alloying elements. For instance, the development of a family of cobalt-free maraging steels in the late 1970s was solely due to the sharp rise in cobalt pricing [8]. Consequently, understanding the correlations between alloy composition, processing parameters, microstructures and final properties of maraging steels is of great importance since they govern alloy design and production. Moreover, the fact that a single grade of maraging steel cannot easily be heat-treated to produce widely different strength levels necessitates different grades of steels, each tailored to a specific strength level. This makes the understanding of such correlations even more desirable.

Essentially there are two ways to understand such correlations. First, one can adopt a model that describes physical relations between parameters, and verify this model using experiments [911]. However, an explicit physical model that quantitatively describes all the relationships between alloy composition, processing parameters and the final properties of maraging steels does not exist. Alternatively, a model can be created by applying statistical techniques to the existing production data [12]. Early attempts usually employed multilinear regression (MLR) methods. However, in maraging steels, rather strong interactions can occur with specific combinations of elements, such as Co and Mo [13]. Such effects are not simply the sum of the influences of each single element.

In this consideration, artificial neural network (ANN) modelling is a powerful alternative. It is essentially an advanced statistical analysis method. Since little prior knowledge of the physical background of the processes is required, this method can dramatically benefit the industry, as industrial metallurgists often have to solve their problems without full comprehension of the scientific background. Though this modelling technique is relatively new, it has found a variety of applications in the field of materials science [14-20], including the recent work carried out at Queen's [21-23].

In the work reported in this paper, the aim was to design an ANN for the prediction of the mechanical properties of maraging steels as a func- tion of alloy composition, processing parameters, and working temperature. Martensitic transformation start temperature (Ms) as a function of alloy chemistry is also studied because it has to be closely controlled for maraging steels. This model will benefit the development of future alloys by optimising composition design and processing.

\section{Model development}

ANN modelling is basically a non-linear statistical analysis technique. It is essentially a 'black box' linking input data to output data using a particular set of non-linear functions. It provides a way of using examples of a target function to find the coefficients that make a certain mapping function approximate the target function as closely as possible. A fully connected three-layer feedforward network is shown in Fig. 1. It consists of three layers: the input, hidden, and output layers. Each node in the input layer represents in the network the value of one independent variable. The nodes in the hidden layer are only for computation purpose. Each of the output nodes computes one dependent variable. More details about the principles of ANN modelling can be found elsewhere [24,25]. As Hornik et al. [26] have shown that a three-layer (one input, one hidden, and one output) ANN with sigmoid transfer functions can map any function of practical interest, a threelayer neural network model is used in the present work.

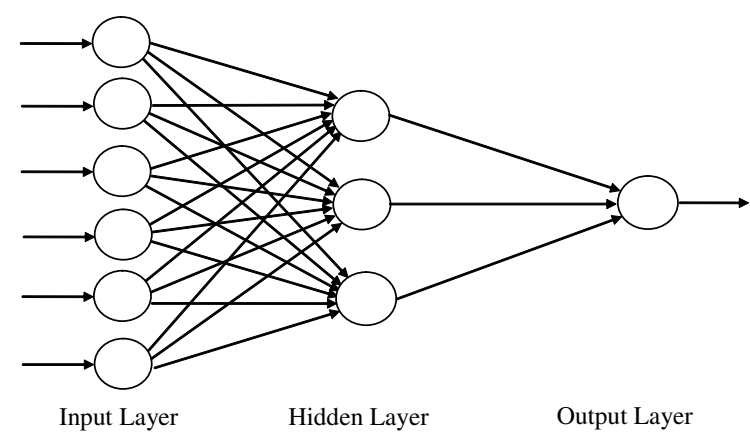

Fig. 1. Structure of a neural network. 
ANN modelling normally follows these steps: determination of input/output parameters, data collection; analysis and pre-processing of the data; training of the neural network; testing of the trained network; and using the trained network for simulation and prediction. Model training includes the choice of architecture, training algorithms and parameters of the network. The development of this model has followed these steps.

\subsection{Input and output parameters}

The selection of the property-related parameters, or input parameters, is based on the physical background of how the target property is determined. Omitting the parameters which are not important benefits the development of the model and simplifies further application. For maraging steels, there are two major thermal treatment processes: austenitising and ageing. A cold deformation procedure is sometimes used between the two treatments to increase the achievable strength level. As long as the austenitising process ensures a full transformation to austenite, the temperature and time only marginally affect the mechanical properties after ageing, in that an increase in austenitising temperature $\left(T_{\text {aus }}\right)$ or time $\left(t_{\text {aus }}\right)$ usually leads to slightly better toughness and a slight drop in strength. Therefore, it was decided that $T_{\text {aus }}$ and $t_{\text {aus }}$ should not be used as inputs. In practice, the chosen $T_{\text {aus }}$ and $t_{\text {aus }}$ should be sufficiently high and long to ensure a fully austenitic structure, and then as low and short as possible to avoid austenite grain growth. The cooling method after austenitising is usually air-cooling or waterquenching (occasionally oil-quenching). It is chosen to ensure a full martensitic transformation, and was not taken as an input parameter either. The cold deformation and ageing treatment are important to the mechanical properties of maraging steels [3]. Therefore, the input parameters include cold deformation degree $(\varepsilon)$, ageing temperature $\left(T_{\text {age }}\right)$, and ageing time $\left(t_{\text {age }}\right)$. As maraging steels are frequently used and sometimes essential for many high-temperature applications, the working temperature is taken as another input parameter to the ANN model.



Fig. 2. Schematic diagram of the ANN model for prediction of properties of maraging steels.

Therefore, the inputs for the present model consist of alloy composition, processing parameters (including $\varepsilon, T_{\text {age }}$, and $t_{\text {age }}$ ), and working temperature. The outputs of the ANN model are the mechanical properties including ultimate tensile strength (UTS), $0.2 \%$ yield strength (YS), elongation (EL), reduction in area (RA), hardness (HV), notched tensile strength (NTS), Charpy impact energy $(A \kappa)$, and fracture toughness $\left(K_{\mathrm{Ic}}\right)$, as well as martensitic transformation start (Ms) temperature. The structure of the ANN model is shown in Fig. 2.

\subsection{Database construction and analysis}

The performance of an ANN model depends on the dataset used for its training. Construction of a reliable dataset is therefore the first critical step. The dataset was constructed by collecting available data on properties of maraging steels and lowcarbon PH steels from literature [27-33]. In total, 2959 input/output data pairs were collected. All the data was for the longitudinal direction. One should be aware that the difference in strength is not significant between longitudinal and transverse directions, but toughness is more strongly directional [30,34-36]. Three types of hardness data, HB, HRC, and HV, were collected. Before model training, the $\mathrm{HB}$ and $\mathrm{HRC}$ data were converted to $\mathrm{HV}$ using a conversion table especially for martensitic steels [37]. When the amount of $\mathrm{C}$ is not given for an alloy (less than 50 cases), it was set as 
Table 1

Statistical analysis of the alloy composition as input variables ( $\mathrm{wt} \%)$

\begin{tabular}{llllllllllllll}
\hline & $\mathrm{C}$ & $\mathrm{Al}$ & $\mathrm{Co}$ & $\mathrm{Cr}$ & $\mathrm{Cu}$ & $\mathrm{Mn}$ & $\mathrm{Mo}$ & $\mathrm{Nb}$ & $\mathrm{Ni}$ & $\mathrm{Si}$ & $\mathrm{Ti}$ & $\mathrm{V}$ & $\mathrm{W}$ \\
\hline No. $^{\text {a }}$ & 2959 & 1479 & 1402 & 1326 & 477 & 1890 & 1782 & 316 & 2505 & 2183 & 1831 & 45 & 281 \\
Min & 0.001 & 0 & 0 & 0 & 0 & 0 & 0 & 0 & 0 & 0 & 0 & 0 & 0 \\
Max & 0.085 & 3.2 & 20.0 & 26.0 & 4.0 & 8.0 & 17.5 & 3.1 & 25.5 & 2.9 & 2.5 & 10.0 & 9.6 \\
Mean & 0.020 & 0.24 & 5.7 & 6.6 & 1.0 & 1.3 & 3.6 & 0.13 & 7.2 & 0.32 & 0.57 & 0.34 & 1.6 \\
Standard & 0.029 & 0.11 & 4.8 & 5.1 & 0.4 & 0.4 & 2.8 & 0.03 & 11.7 & 0.16 & 0.46 & 0.02 & 0.5 \\
$\quad$ deviation & & & & & & & & & & & &
\end{tabular}

${ }^{\mathrm{a}}$ The number of alloys that contains the relevant element.

$0.03 \%$ by weight. A statistical analysis of the chemical composition of the alloys used is shown in Table 1, containing 13 elements: $\mathrm{C}, \mathrm{Al}, \mathrm{Co}, \mathrm{Cr}$, $\mathrm{Cu}, \mathrm{Mn}, \mathrm{Mo}, \mathrm{Nb}, \mathrm{Ni}, \mathrm{Si}, \mathrm{Ti}, \mathrm{V}$, and W. Elements B and $\mathrm{Zr}$ are not efficient alloying elements and their uses were rare in the development of maraging steels. Element Be, though classified as a strong hardener, has not been widely employed because of toxicity concerns. Influences from residual impurities $\mathrm{Ca}, \mathrm{N}, \mathrm{O}, \mathrm{P}$, and $\mathrm{S}$ were ignored.

For each of the different output properties the number of data pairs collected varied, and an analysis of the database regarding each property is shown in Table 2 . The data availability and temperature range for each property are also shown in this table. This defines the range of application of the ANN model. Although most of the data is for properties at room temperature, a significant amount of data at either cryogenic or high temperature is also available. The availability of data at different temperature ranges is shown in Fig. 3. Since hardness measurement must be carried out at room temperature, the above data distribution analysis does not apply to hardness data.

As expected, the model, though as a black-box, will be more influenced by steels with many data points and therefore biased. This should not be considered as a disadvantage however, as the trust worthiness will be higher where the number of data points is greater.

\subsection{Neural network training}

Many parameters can be altered in order to get a well-trained model, among which an important one is the training algorithm. It has become stan- dard for some years to train ANNs by a method called backpropagation. The term backpropagation refers to the manner in which the gradient is computed for non-linear multilayer networks. The early standard algorithm consists of assigning a random initial set of weights to the neural network, then presenting the data inputs, one set at a time, and adjusting the weights with the aim of reducing the corresponding output error. This was repeated for each set of data, and then the complete cycle was repeated until an acceptably low value of the sum of squares error was achieved. Such an algorithm is usually both inefficient and unreliable, requiring many iterations to converge if it converges at all. Therefore, a number of variations of the standard algorithm have been developed, based on other optimisation techniques, with a variety of computation and storage advantages [38]. The two most popular algorithms are Levenberg-Marquardt algorithm and Bayesian regularization (TRAINBR). ${ }^{2}$ The former method is the fastest training algorithm for networks of moderate size. It has a memory reduction feature for use when the training set is large. The time required for training can be dramatically reduced using this method. However, it is sometimes difficult to find the best model using this algorithm. Bayesian regularization (BR) is a modification of the Levenberg-Marquardt algorithm for obtaining networks which generalize well. It

\footnotetext{
${ }^{2}$ MatLab command for the corresponding function. PREMNMX, POSTMNMX, TRAMNMX, TANSIG, PURELIN, and NEWGRNN, which appear later, are also MatLab commands.
} 
Table 2

Analysis of the properties as output data

\begin{tabular}{|c|c|c|c|c|c|c|c|c|c|}
\hline & $\begin{array}{l}\text { UTS } \\
(\mathrm{MPa})\end{array}$ & YS (MPa) & $\begin{array}{l}\text { NTS } \\
(\mathrm{MPa})\end{array}$ & EL (\%) & RA (\%) & $A \kappa(\mathrm{J})$ & $\begin{array}{l}K_{\mathrm{Ic}}(\mathrm{MPa} \cdot \\
\left.\mathrm{m}^{1 / 2}\right)\end{array}$ & HV & $\mathrm{Ms}\left({ }^{\circ} \mathrm{C}\right)$ \\
\hline No. & 922 & 951 & 220 & 801 & 671 & 500 & 107 & 1655 & 215 \\
\hline Min & 252 & 283 & 68 & 0 & 0.7 & 1 & 8 & 89 & -197 \\
\hline Max & 3660 & 2531 & 396 & 43 & 85 & 213 & 260 & 962 & 684 \\
\hline Mean & 1494 & 1452 & 287 & 13 & 53 & 50 & 86 & 440 & 245 \\
\hline $\begin{array}{l}\text { Standard } \\
\text { deviation }\end{array}$ & 441 & 442 & 71 & 6 & 18 & 43 & 60 & 154 & 178 \\
\hline $\begin{array}{l}\text { Data } \\
\text { availability }\end{array}$ & All & All & No W & All & $\begin{array}{l}\text { No defor- } \\
\text { mation }\end{array}$ & $\begin{array}{l}\text { No defor- } \\
\text { mation }\end{array}$ & $\begin{array}{l}\mathrm{No} \mathrm{Cu}, \\
\mathrm{Nb}, \mathrm{V}, \\
\text { and } \mathrm{W}\end{array}$ & All & No W \\
\hline $\begin{array}{l}\text { Tempera- } \\
\text { ture range } \\
\left({ }^{\circ} \mathrm{C}\right)\end{array}$ & $\begin{array}{l}-196 \text { to } \\
816\end{array}$ & $\begin{array}{l}-196 \text { to } \\
649\end{array}$ & $\begin{array}{l}-196 \text { to } \\
343\end{array}$ & $\begin{array}{l}-196 \text { to } \\
816\end{array}$ & $\begin{array}{l}-196 \text { to } \\
816\end{array}$ & $\begin{array}{l}-196 \text { to } \\
788\end{array}$ & $\begin{array}{l}-137 \text { to } \\
316\end{array}$ & $\begin{array}{l}\text { Room } \\
\text { tempera- } \\
\text { ture }\end{array}$ & - \\
\hline
\end{tabular}

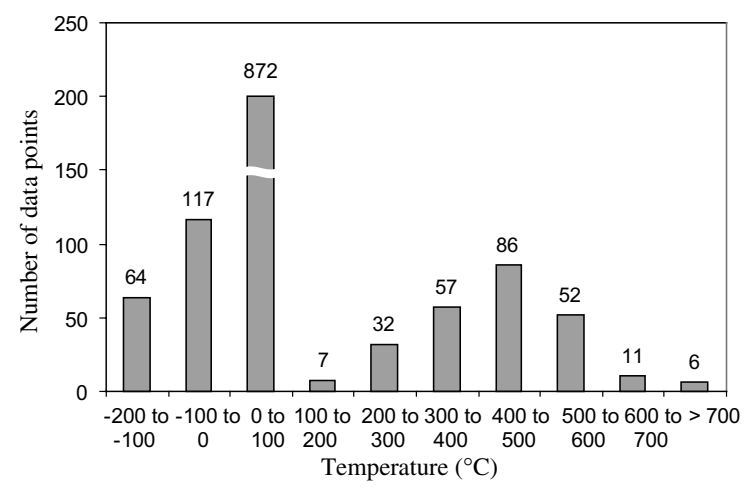

Fig. 3. Distribution of data on mechanical properties versus testing temperature (The 1655 data pairs for hardness were not included in this analysis.).

reduces the difficulty in determining the optimum network parameters. This algorithm itself was first used in modelling the Ms temperature, with twothirds of the data for model training and one-third for model testing. The performance of the resulting model on the testing data was not good. Overfitting seems to have taken place. A method to avoid the overfitting problem is the early stopping technique. This was then used in combination with Bayesian regularization. The data was divided into three groups, one-half for the training set, onequarter for the validation set and one-quarter for the test set. The model obtained through this way demonstrated better performance than using TRAINBR itself. Therefore, training of ANN models was carried out by combining the early stopping technique with TRAINBR algorithm throughout the present work.

Since backpropagation may not always find the correct weights for the optimum solution, a number of re-initializations and re-trainings of the network were carried out to obtain the best solution. Neural networks of other types may also be considered in model creation, such as radial basis function (RBF) networks. Such networks may require more neurons than standard feedforward backpropagation networks, but often they can be designed in a fraction of the time it takes to train standard feedforward networks [38]. RBF networks were created to model the Ms temperature of maraging steels (NEWGRNN). The performance is not as good as the model achieved using backpropagation algorithm, though model training takes less time. Therefore, RBF networks were not used in the present study. Other new generation learning systems, such as support vector machines, are described in dedicated books $[39,40]$. Comparatively, the standard ANN method used in the present work is well developed and has been proven to be suitable for modelling metallurgical correlations [22-24].

Separate models were developed for individual properties in the present work. This is because training time increases dramatically when the number of outputs increases. Therefore, setting up a series of ANN models where each model deals 
with only one output value significantly simplifies and speeds up the training of the ANN model. On the other hand, the data available for each individual output property are different. For instance, for one set of input variables whose corresponding UTS is known, the fracture toughness may not be measured. This makes it difficult to setup one single model where both UTS and fracture toughness can be trained. Such models, each corresponding to one individual output property were incorporated into one integrated model, as schematically shown in Fig. 2. When one set of input parameters is fed into the integrated model, different models, each for one output, will be employed to calculate the set of output properties.

\subsection{Pre-treatment of ageing time $t_{\text {age }}$}

A close study of the hardness database showed that the input parameter ageing time $\left(t_{\text {age }}\right)$ ranges from 0.001 to $1968 \mathrm{~h}$ with a heavily skewed distribution (Fig. 4(a)). The distribution is presented as a form of histograms in 10 equal ranges between the minimum and maximum values. The obtained ANN model did not perform well when untreated ageing time was used as input. When the $\ln \left(t_{\text {age }}\right)$ value was used as an input parameter, the performance of the ANN model was different. The distribution of $\ln \left(t_{\text {age }}\right)$ is shown in Fig. 4(b). The performance of the model after this treatment was much better compared with the model without treatment, as shown in Table 3. This is because, most statistical learning techniques, including ANN modelling, can improve model performance by normalizing the training data. Taking a logarithm of the parameter $t_{\text {age }}$ in the present work is akin to a normalization procedure. As shown in Fig. 4, such treatment makes the distribution of this input parameter close to normal distribution, which is more readily dealt with by ANN modelling to achieve better performance. Such treatment on $t_{\text {age }}$ was also carried out for modelling other properties since ln-treatment always leads to a more balanced input distribution.

Other parameters such as data pre-processing methods, transfer functions and the number of hidden nodes were also altered to achieve the best model. A program was written to identify the
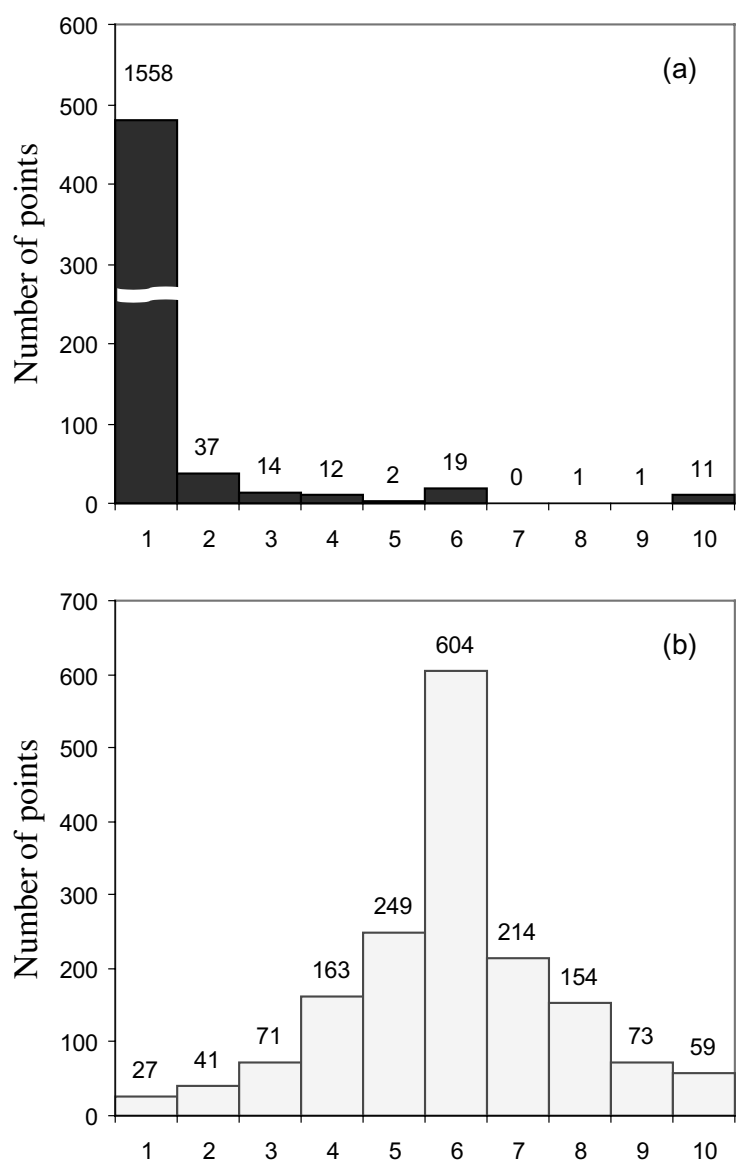

Fig. 4. Distribution of the input parameter $t_{\text {age }}$ without (a) and with (b) ln-treatment for modelling HV of maraging steels.

model with the best performance after model training has been undertaken for several hundred times with different training parameters. When each training parameter was altered manually, about 50-100 times of training were carried out to find the best model for this set of training parameters. This model was then stored for later comparison. Another parameter was then altered, followed by $50-100$ times of training to achieve the best model corresponding to this set of training parameters. This model was then stored for later comparison. In the end, the obtained models, of best performance for different training parameters, were compared with each other and the best model was picked up for use of future prediction. For example, the optimised model for Ms modelling is 
Table 3

Comparison between two hardness models without and with ln-treatment of ageing time with the mean error and the error deviation as defined in Eqs. (1) and (2), respectively

\begin{tabular}{|c|c|c|c|c|c|c|}
\hline \multirow[t]{2}{*}{ Treatment } & \multirow[t]{2}{*}{ Range (h) } & \multicolumn{2}{|c|}{ Input analysis } & \multicolumn{2}{|c|}{ Prediction analysis } & \multirow{2}{*}{$\begin{array}{l}R \text { in linear } \\
\text { regression }\end{array}$} \\
\hline & & Mean error & $\overline{\text { Error deviation }}$ & Mean error & Error deviation & \\
\hline Without & $0.001-1968 \mathrm{~h}$ & 60.1 & 223.3 & - & $>40$ & - \\
\hline With & $-6.9-7.6$ & 1 & 2.7 & 0 & 32 & 0.976 \\
\hline
\end{tabular}

of 12-6-1 structure, with functions PREMNMX, POSTMNMX and TRAMNMX for pre- and post-processing. PREMNMX was used to scale inputs and targets so that they fall in the range $[-1,1]$. Such pre-processing procedure can make the neural network training more efficient. POSTMNMX, inverse of PREMNMX, is used to convert data back to standard units. TRAMNMX normalizes data using previously computed minimums and maximums by the PREMNMX function. It is used to pre-process new inputs to networks which have been trained with data normalized with PREMNMX. The transfer functions employed were the hyperbolic tangent sigmoid function (TANSIG) and the linear function (PURELIN). Detailed information about these functions can be found in the manual of Neural Network Toolbox for MatLab [38].

\section{Results and discussion}

\subsection{Model performance}

Two parameters were used to evaluate the performance of ANN modelling, 'mean error' and 'error deviation' as defined in Eqs. (1) and (2):

Mean error $=\frac{1}{n} \sum_{i=1}^{n}\left(A_{i}-T_{i}\right)$

Error deviation

$$
=\sqrt{\frac{\left(n \sum\left(A_{i}-T_{i}\right)^{2}-\left(\sum\left(A_{i}-T_{i}\right)\right)^{2}\right)}{n(n-1)}}
$$

In the above equations, $A_{i}$ is the calculated result for the $i$ th alloy, $T_{i}$ is the corresponding experimental value and $n$ is the number of alloys in the sample set. When two models are of close mean errors, both of which are smaller than the target error (e.g. $5{ }^{\circ} \mathrm{C}$ for Ms temperature), the one of smaller error deviation is considered to be better.

\subsubsection{Modelling of Ms temperature}

The Ms temperature of maraging steels must be closely controlled in order to ensure complete transformation of austenite to martensite. Because Ms is mainly a function of alloy chemistry, the usual requirement for the composition throughout the development of maraging steels is to guarantee an Ms above room temperature. It is highly desirable to quantitatively understand the influence of alloying elements on Ms temperature of steels. For this purpose, empirical relationships between Ms and chemical composition of low-carbon highstrength steels have been derived by employing MLR analysis [41-43]. However, the existing expressions neither considered the interactions between individual alloying elements, nor were they fully tested for alloys with many different types of alloying elements since most of the data was for ternary or quaternary alloys. In the current database for Ms modelling, most of the data are for alloys with more than four elements. In total, 215 data pairs were collected. The input variables were the concentration of 12 elements: $\mathrm{C}, \mathrm{Al}, \mathrm{Co}, \mathrm{Cr}$, $\mathrm{Cu}, \mathrm{Mn}, \mathrm{Mo}, \mathrm{Nb}, \mathrm{Ni}, \mathrm{Si}, \mathrm{Ti}$, and $\mathrm{V}$ (no W).

The performance of the resulting ANN model on different datasets, namely all data, training, validation, and test sub-datasets, is shown in Fig. 5. The mean error of this model on the whole dataset is $-1{ }^{\circ} \mathrm{C}$, with error deviation $32{ }^{\circ} \mathrm{C}$. On the testing dataset, the mean error and error deviation are -2 and $46{ }^{\circ} \mathrm{C}$ respectively. For comparison, the error deviation of a MLR analysis of the whole dataset is $64{ }^{\circ} \mathrm{C}$ (mean error: $0{ }^{\circ} \mathrm{C}$ ). The influence of each element is shown in Table 4 , 

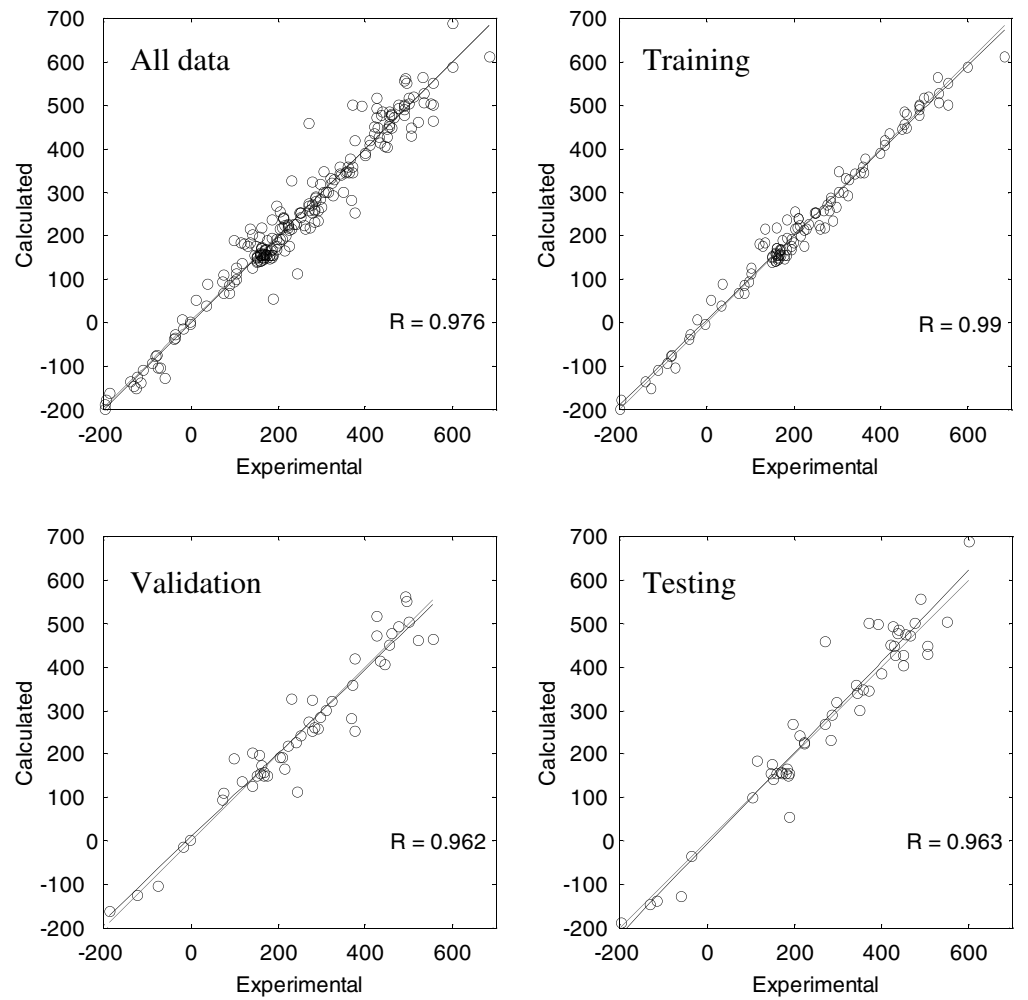

Fig. 5. Performance of ANN model for Ms temperature, for all data, training, validation, and testing data respectively.

together with some previous results for comparison. As can be seen the present results differ very much from previous work [41-43] especially in the effects of Mo and Ti. MLR analyses cannot predict correctly the influence of Co. This is because one of the important roles of $\mathrm{Co}$ in maraging steels is raising the Ms temperature [44,45], therefore increasing the permissible amount of other agehardening alloying elements without leaving residual austenite. It would be a major drawback if such effect cannot be predicted. ANN modelling shows its clear advantage in this aspect, as will be discussed later.

\subsubsection{Modelling of the mechanical properties}

UTS and Charpy impact energy $(A \kappa)$ were used to demonstrate the performance of the ANN models of mechanical properties (Figs. 6 and 7). As can be seen in Fig. 6, the model calculation fits the experimental observation well. The mean error of this model is $-4 \mathrm{MPa}$, with an error deviation
$102 \mathrm{MPa}$. For the test dataset only, the mean error is $-2 \mathrm{MPa}$, with an error deviation of $128 \mathrm{MPa}$. Evidently, the trained model is capable of predicting for new cases. The model for Charpy impact energy also shows good performance, though less accurate than the UTS model. Statistical analysis of the models for all the properties is summarised in Table 5. These models perform well overall judging by the performance of the test datasets. The number of nodes in the hidden layer was 6 for all of the models, except for $K_{\text {Ic }}$ (3 nodes).

Only the data in training and validation datasets were used in the model optimisation process. The test dataset is not involved in the model training process, but solely for the testing purpose. Therefore, the accuracy of an ANN model in prediction is clearly demonstrated by its performance on the testing dataset (Table 5). The performance of ANN models for EL, RA, and $A \kappa$ is not as good as that for UTS, YS, and HV. 
Table 4

Influence of alloying elements on Ms temperature from MLR analysis

\begin{tabular}{|c|c|c|c|c|c|c|c|c|c|c|c|c|c|}
\hline $\begin{array}{l}\text { Con- } \\
\text { stant } \\
\left({ }^{\circ} \mathrm{C}\right)\end{array}$ & $\mathrm{C}$ & $\mathrm{Al}$ & Co & $\mathrm{Cr}$ & $\mathrm{Cu}$ & $\mathrm{Mn}$ & Mo & $\mathrm{Nb}$ & $\mathrm{Ni}$ & $\mathrm{Si}$ & $\mathrm{Ti}$ & $\mathrm{V}$ & Source \\
\hline 549 & -500 & 15.9 & -3.8 & -18.3 & -6 & -22 & 0.2 & -1.6 & -17.5 & -10 & -29 & -54 & $\begin{array}{l}\text { This } \\
\text { work }\end{array}$ \\
\hline 832 & & & -5 & -29 & & & -36 & & -39 & & 0 & & $\begin{array}{l}\text { Ref. } \\
{[41]}\end{array}$ \\
\hline 561 & -474 & & & -17 & & -33 & & & -17 & & & & $\begin{array}{l}\text { Ref. } \\
\text { [42] }\end{array}$ \\
\hline 539 & -423 & & & -12.1 & & -30.4 & -7.5 & & -17.7 & & & & $\begin{array}{l}\text { Ref. } \\
\text { [43] }\end{array}$ \\
\hline
\end{tabular}

$\mathrm{Ms}=$ Constant $+\sum_{i} a_{i} x_{i}$, where $x_{i}$ is the concentration of the $i$ th element in weight percent and $a_{i}$ is the coefficient, the values of which are given in the table.
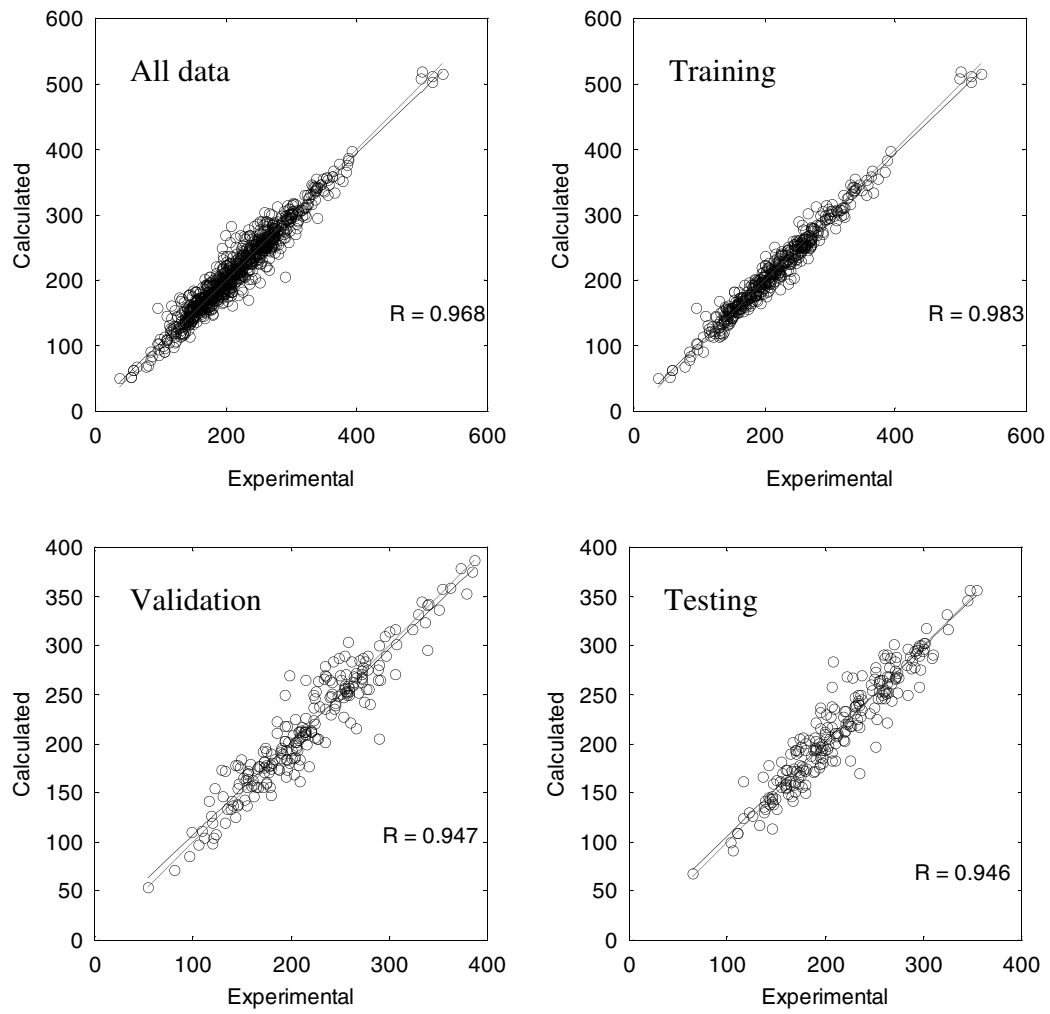

Fig. 6. Performance of ANN model for UTS, for all data, training, validation, and testing data respectively.

This is because ductility-related parameters are more easily affected by experimental factors, such as specimen condition and dimension, than strength parameters. The performance of the model for fracture toughness is surprisingly bet- ter than that of EL, RA, and $A \kappa$. Due to the lesser quantity of $K_{\text {Ic }}$ data available, the number of the hidden nodes was set as 3 . Nevertheless, caution should be exercised when this model is used. 

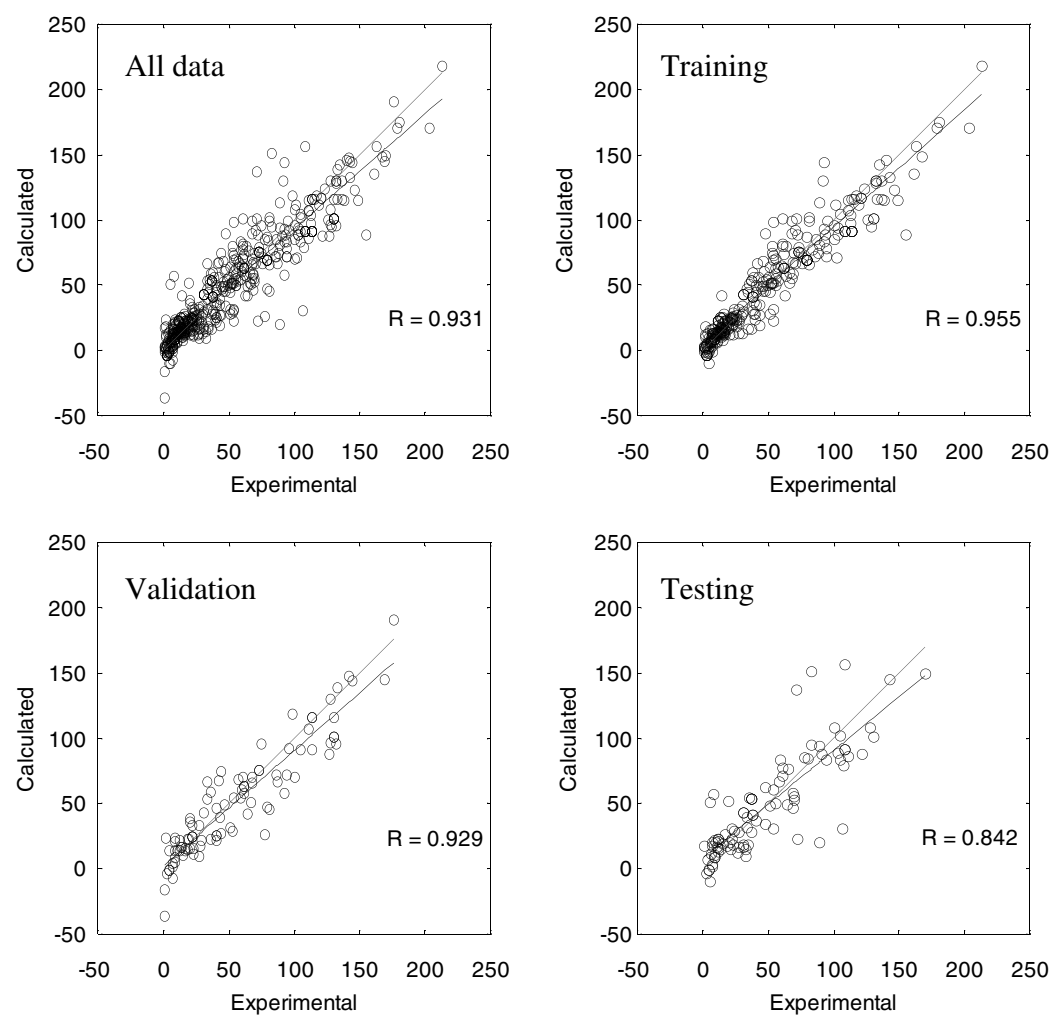

Fig. 7. Performance of ANN model for $A \kappa$, for all data, training, validation, and testing data respectively.

Table 5

Analysis of the output data for whole and test datasets of neural network for prediction of the mechanical properties and Ms temperature of maraging steels

\begin{tabular}{|c|c|c|c|c|c|c|}
\hline & \multicolumn{3}{|l|}{ All data } & \multicolumn{3}{|l|}{ Test data } \\
\hline & Mean error & Error deviation & $\begin{array}{l}R \text { in linear re- } \\
\text { gression }\end{array}$ & Mean error & Error deviation & $\begin{array}{l}R \text { in linear re- } \\
\text { gression }\end{array}$ \\
\hline UTS (MPa) & -4 & 102 & 0.968 & -2 & 128 & 0.946 \\
\hline YS (MPa) & 6 & 103 & 0.963 & 14 & 137 & 0.954 \\
\hline NTS (MPa) & -3 & 186 & 0.935 & -1 & 288 & 0.816 \\
\hline EL $(\%)$ & 0.1 & 2.8 & 0.887 & -0.4 & 3.2 & 0.858 \\
\hline RA $(\%)$ & 0.2 & 8.8 & 0.903 & 1.6 & 10.8 & 0.886 \\
\hline$A \kappa(\mathrm{J})$ & -0.8 & 15.8 & 0.931 & -0.3 & 21.7 & 0.842 \\
\hline$K_{\mathrm{Ic}}\left(\mathrm{MPa} \cdot \mathrm{m}^{1 / 2}\right)$ & 0.3 & 9.2 & 0.988 & -0.2 & 12.3 & 0.969 \\
\hline HV & 0 & 32 & 0.978 & -3 & 36 & 0.976 \\
\hline Ms $\left({ }^{\circ} \mathrm{C}\right)$ & -1 & 32 & 0.976 & -2 & 46 & 0.963 \\
\hline
\end{tabular}

3.2. Comparison of model predictions with experimental data

\subsubsection{Ms temperature}

Following the development of maraging steels, the most important family of grades are C200,
C250, C300, C350, and C450 (the strength level in $k s i$ is indicated in the product grades). They were tailored to certain strength levels by mainly varying alloy composition. The first four grades were based on the classical $\mathrm{Fe}-18 \mathrm{Ni}$ system, with different amounts of $\mathrm{Co}, \mathrm{Mo}, \mathrm{Ti}$, and $\mathrm{Al}$, whereas 
$\mathrm{C} 450 \quad(\mathrm{Fe}-6 \mathrm{Ni}-15 \mathrm{Cr}-1.5 \mathrm{Cu}-1 \mathrm{Mn}-1 \mathrm{Si})$ is very much different in that it contains no cobalt. The Ms temperatures of these alloys calculated from the ANN model are compared with experimental values in Fig. 8. It can be seen that they are in good agreement.

\subsubsection{Room temperature properties}

Since most of the data used was for mechanical properties at room temperature, the highest accuracy of the neural network is expected for the prediction of room temperature properties. $\mathrm{PH} 13-$ 8, a martensitic precipitation hardening $(\mathrm{PH})$ stainless steel, was chosen here to test the influence of ageing treatment on mechanical properties. The alloy offers good mechanical properties under severe environmental conditions, superior to $\mathrm{PH} 17-4$ and PH15-5 stainless steels [29]. Common treatments of this alloy include ageing at 510, 538, 566, 593 or $621{ }^{\circ} \mathrm{C}$ for $4 \mathrm{~h}$. The influence of such treatments on UTS, YS, EL, RA, and HV properties of PH13-8 is shown in Fig. 9. The models perform well; predicting results very close to the experimental results. The accuracy of the ANN models is best for hardness. This is probably because the number of training data pairs was largest for the hardness as compared to the other mechanical properties. However, the accuracy of the network predictions is within the acceptable error range for all the other properties.

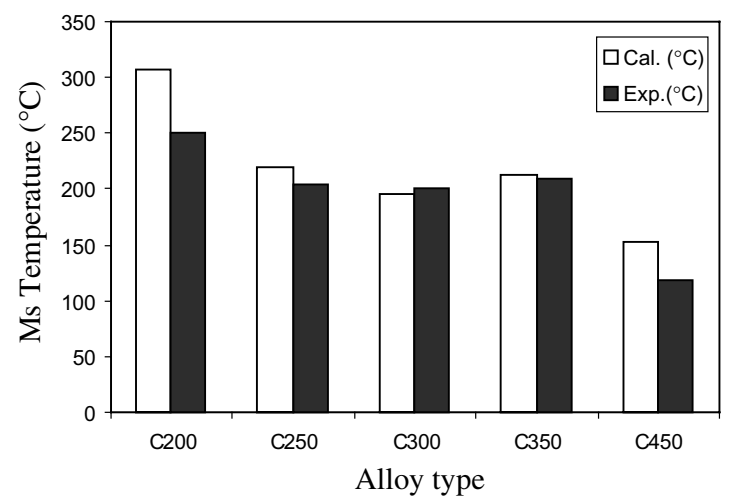

Fig. 8. Comparison of the Ms temperature calculated from the ANN model with experimental values.
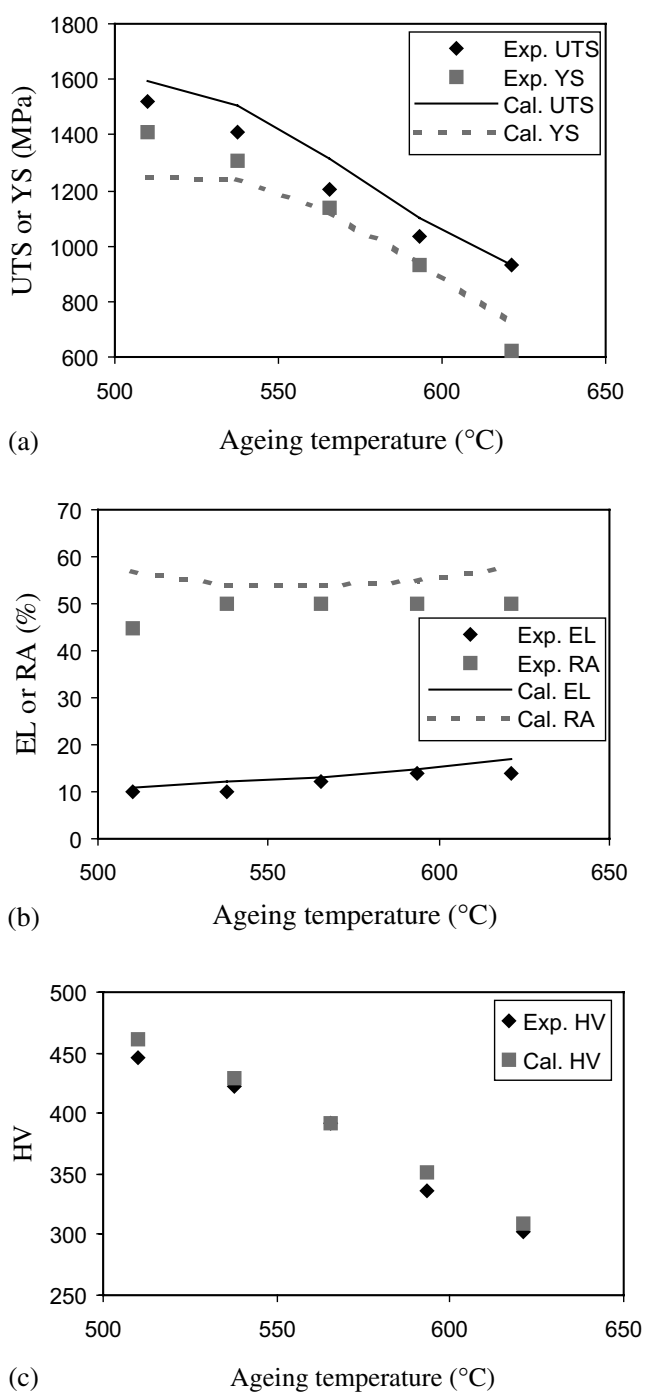

Fig. 9. Comparison of the room temperature properties calculated from the ANN model with experimental values for PH13-8, aged at five different temperatures for $4 \mathrm{~h}$ : (a) UTS and YS, (b) EL and RA, and (c) HV.

\subsubsection{Properties over a wide temperature range}

One important feature of the present ANN models is the ability to simulate materials behaviour over a wide temperature range. PH13-8 steel, with excellent resistance to oxidation up to approximately $593{ }^{\circ} \mathrm{C}$, was chosen here as an example. The properties such as UTS, YS, EL, and RA as functions of working temperature were 



(b)

Fig. 10. Comparison of ANN model calculations with experimental values for PH13-8, aged at $538^{\circ} \mathrm{C}$ for $4 \mathrm{~h}$ : (a) UTS and YS, and (b) EL and RA.

calculated. The material was aged at $538^{\circ} \mathrm{C}$ for $4 \mathrm{~h}$ and the testing temperature ranged between -196 and $560{ }^{\circ} \mathrm{C}$. Comparison between model calculations and experimental measurements is given in Fig. 10. The models predict reasonably well from room temperature to $300{ }^{\circ} \mathrm{C}$. The properties of a 450-grade alloy $(\mathrm{Fe}-15 \mathrm{Cr}-6 \mathrm{Ni}-1 \mathrm{Mn}-1 \mathrm{Si}-$ $0.75 \mathrm{Mo}-0.3 \mathrm{Nb}$ ) was also studied over a wide temperature range. The ageing treatment was at $482{ }^{\circ} \mathrm{C}$ for $4 \mathrm{~h}$. Comparison between model calculations and experimental results is shown in Fig. 11. The model again predicts well when temperature is up to $300{ }^{\circ} \mathrm{C}$. Higher temperature leads to larger deviations from the experimental values. This is because there is a lack of experimental data at cryogenic or elevated temperatures in the current database compared with room-temperature data. Therefore the material behaviour at elevated temperatures cannot be well represented. Although there are not many data between room

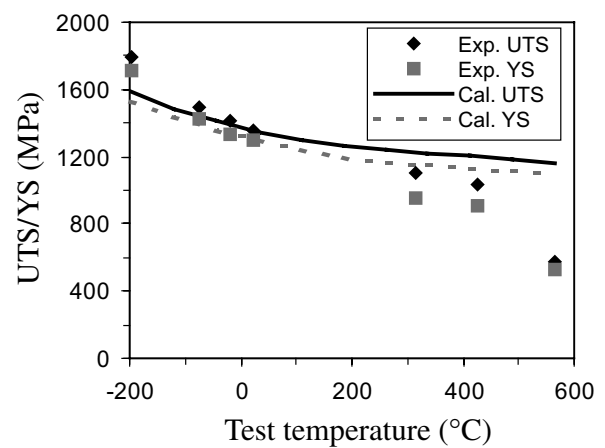

Fig. 11. Comparison of ANN model calculations with experimental values for a 450 grade maraging steel, aged at $482{ }^{\circ} \mathrm{C}$ for $4 \mathrm{~h}$.

temperature and $300{ }^{\circ} \mathrm{C}$, as the material behaviour remains similar within this temperature range, it is easy to predict it with reasonable accuracy. Caution should be exercised when properties at temperatures above $300{ }^{\circ} \mathrm{C}$ are calculated using the ANN models.

\section{Application of model}

As the ANN models perform well overall, they can be used to predict Ms and mechanical properties of maraging steels with sufficient accuracy within the data range used in model development. In maraging steels, the interactions between $\mathrm{Co}$ and Mo are complicated. Many alloy developments were based on these interactions. They have been studied here based on model calculations. Since the models have been designed on statistical models, and not on physical theories, some of the results will be discussed from the metallurgical point of view.

\subsection{Interactions between $C o$ and $M o$ on $M s$ temperature}

The influence of $\mathrm{Co}$ on $\mathrm{Ms}$ temperature of maraging systems is simulated using the ANN model. The interaction between Co and Mo is also studied here. The alloy system is chosen to be based around the chemical composition of the 


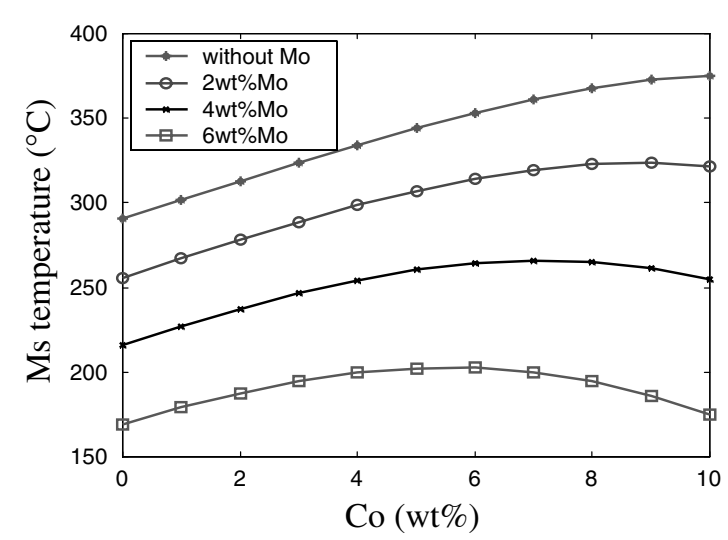

Fig. 12. Influence of $\mathrm{Co}$ and $\mathrm{Mo}$ on the Ms temperature of $\mathrm{Fe}-$ $18 \mathrm{Ni}-\mathrm{Co}-\mathrm{Mo}$ system.

classical $\mathrm{Fe}-18 \mathrm{Ni}$ maraging steels, $\mathrm{Fe}-0.01 \mathrm{C}-$ $0.1 \mathrm{Al}-18 \mathrm{Ni}-0.4 \mathrm{Ti}-9 \mathrm{Co}-4 \mathrm{Mo}$ (referred to as $\mathrm{Fe}-$ $18 \mathrm{Ni}-9 \mathrm{Co}-4 \mathrm{Mo}$ in the later context). The amounts of $\mathrm{Co}$ and Mo are variables with values as low as zero so that the influence from these elements can be shown (Fig. 12). As can be seen Co always raises the Ms temperature when no Mo is present, as observed by Yeo [45]. However, with Mo present, the influence of Co becomes complicated. It has been found experimentally that with the addition of $1.5 \% \mathrm{Mo}$, Co decreases Ms temperature when its amount is higher than $15 \%$ [46]. Such tendency can be seen in the curve corresponding to $2 \%$ Mo in Fig. 12, where the increase in Ms with Co ceases when Co is higher than about 9\%. From the ANN model, an amount of Co of above $6 \%$ will cause a reduction in Ms when Mo is 6\%. The increase of Mo always suppresses Ms, and the absolute value of the reduction is enhanced by the increase in the percentage of Co in the alloys $[41,45,46]$.

\subsection{The combined influence of Co and Mo on age hardening kinetics}

The influence of $\mathrm{Co}$ and Mo on the age hardening kinetics of a $\mathrm{Fe}-18 \mathrm{Ni}-4 \mathrm{Mo}$ system at $482{ }^{\circ} \mathrm{C}$ was simulated using the ANN model (Fig. 13). The rate of the precipitation is reflected by the increase in hardness at early stages of the ageing process. It can be seen from Fig. 13 that the rate of increased hardness of systems with Co is greater than for the

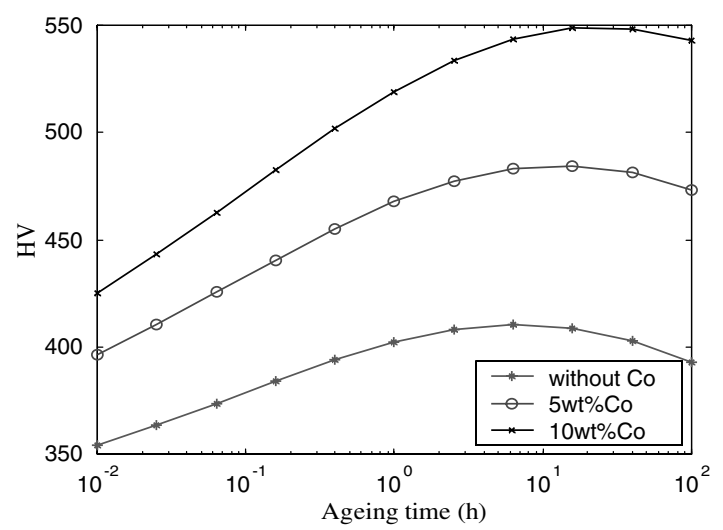

Fig. 13. Influence of $\mathrm{Co}$ on the precipitation kinetics of $\mathrm{Fe}-$ $18 \mathrm{Ni}-\mathrm{Co}-4 \mathrm{Mo}$ system.

system without Co. The hardness increase at the peak position of the Co-containing systems is much higher than that of the Co-free system. This effect can be explained from a metallurgical mechanism. One important role of $\mathrm{Co}$ in maraging steels is to lower the solubility of Mo in martensite, thus producing more densely distributed Mocontaining precipitates to increase the strength. The equilibrium fraction of such precipitates increases, promoting the hardening effect. This has been suggested in early studies and was confirmed by Sha et al. through atom probe study [4-7]. Their results show that the precipitation of Mo is strongly modified by the presence of other elements, most noticeably Co. Without Co the precipitation of Mo takes place much more slowly. In conclusion, the prediction of the neural network model is in agreement with what is expected from a metallurgical viewpoint.

\subsection{The combined influence of Co and Mo on other mechanical properties}

The combined influence of Co and Mo on other mechanical properties is demonstrated here, using UTS and $A \kappa$ as examples. The alloy system is $\mathrm{Fe}-$ $18 \mathrm{Ni}-x \mathrm{Co}-x \mathrm{Mo}$, aged at $482{ }^{\circ} \mathrm{C}$ for $4 \mathrm{~h}$ without cold deformation, and tested at room temperature. The calculated results show that the addition of a small amount of Mo (<about 4\%) decreases the UTS (Fig. 14). Experimentally, Hosomi et al. 




Fig. 14. Influence of $\mathrm{Co}$ and Mo on the UTS of $\mathrm{Fe}-18 \mathrm{Ni}-\mathrm{Co}-$ Mo system.

found that the combined effects of Co and Mo may not be beneficial when the alloying amount of Mo was less than 2\% [47]. In fact, in the commercial maraging steels, the amount of Mo is almost always higher than $2 \%$ [2].

The influence of Co and Mo on Charpy impact energy $(A \kappa)$ is shown in Fig. 15. It can be seen that without Mo, the alloying of Co increases the $A \kappa$ values but such system will have little ageing response [2,3]. Alloying with $2 \%$ Mo significantly increases the $A \kappa$ value of the alloy for Co concentrations lower than $8 \%$, in agreement with the finding of Floreen and Speich [48]. When the amount of Mo is further increased, the $A \kappa$ value is

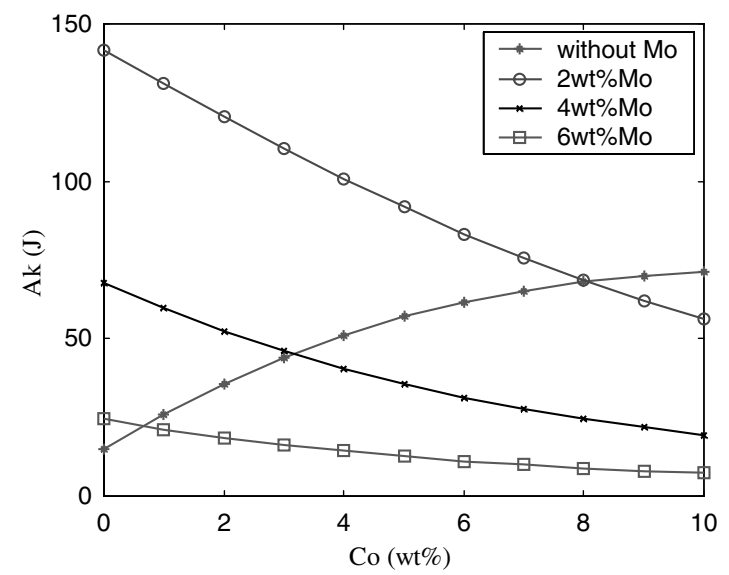

Fig. 15. Influence of $\mathrm{Co}$ and $\mathrm{Mo}$ on the $A \kappa$ value of $\mathrm{Fe}-18 \mathrm{Ni}-$ Co-Mo system. significantly decreased. The establishment of $\mathrm{Fe}-$ $18 \mathrm{Ni}-9 \mathrm{Co}-4 \mathrm{Mo}-0.4 \mathrm{Ti}$ as the nominal composition of the commercial grade C250 is of no surprise as this provides a good combination of strength and toughness. In literature, the UTS and $A \kappa$ of a C250 alloy $(\mathrm{Fe}-18 \mathrm{Ni}-8.5 \mathrm{Co}-5 \mathrm{Mo}-0.4 \mathrm{Ti})$ aged for $5 \mathrm{~h}$ at $480{ }^{\circ} \mathrm{C}$ were given as $1870 \mathrm{MPa}$ and $37 \mathrm{~J}$ [49], in reasonable agreement with the predicted values shown in Figs. 14 and 15.

\subsection{Test on a newly designed alloy-1RK91}

1RK91 (Fe-12Cr-9Ni-4Mo-2Cu-1Ti-0.3Al) is a relatively new maraging grade. It was developed by Sandvik Ltd. and is characterised with good fatigue strength at elevated temperatures. It can reach ultrahigh strength through ageing treatment. The ageing kinetics of 1RK91 are simulated in Fig. 16. The experimental hardness data [50] is presented in the same figure for comparison. The agreement between calculation and experimental measurement is acceptable. The calculated UTS value is $2543 \mathrm{MPa}\left(4 \mathrm{~h}\right.$ ageing at $475{ }^{\circ} \mathrm{C}$, room temperature), within the range of $2450-3000 \mathrm{MPa}$, quoted by Sandvik for aged products [51]. This alloy differs from many previous maraging grades in that it contains about $2 \mathrm{wt} \%$ copper. Without copper, the alloy may still be age-hardened, but the time to achieve considerable hardening will be extraordinarily long, as shown in Fig. 16. In fact, although the good mechanical properties of this

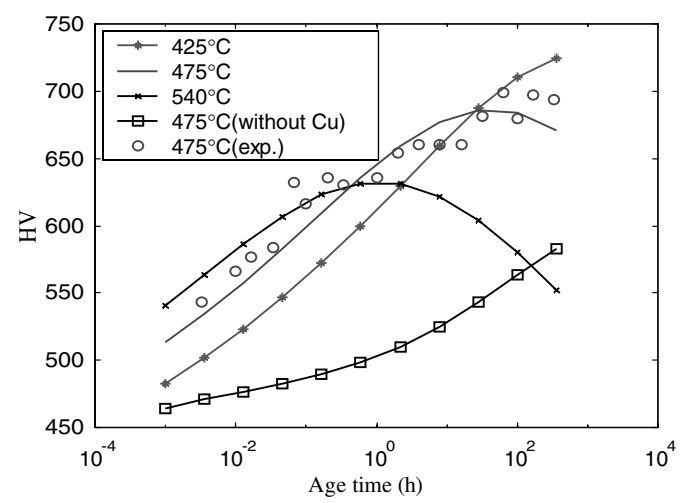

Fig. 16. Age hardening curves of 1RK91 maraging steel from model calculation in comparison with experimental measurements. 
alloy are attributed to precipitates rich in $\mathrm{Ni}, \mathrm{Al}$, and $\mathrm{Ti}, \mathrm{Cu}$ clusters form before these and act as nucleation sites [52]. The application of the neural network model to this new alloy demonstrates that it can be a good guide in the development of new alloys.

As demonstrated from the above results and discussion, these ANN models can predict well even the complicated Co-Mo influences on Ms temperature and mechanical properties of maraging steels. The ANN models have also been demonstrated to be a guide for new alloy design. Based on these models, optimisation of alloy composition and processing parameters can be carried out [23]. For specified working temperature and the required combination of strength and toughness properties, the model can recommend the most economical composition and processing routes and therefore benefit the industry.

\subsection{Suggestions for future work}

ANN modelling is of statistical analysis nature. Its performance is based on the data used for model training. As can be seen from Table 2, the available data for NTS and $K_{\mathrm{Ic}}$ is of small scale. Also, the data available for NTS, RA, $A \kappa, K_{\text {Ic }}$ and Ms do not include one or more input variables. Therefore, from the view of database, it is suggested more data which fill in the above gaps can be collected. The current model is open for development and improvement. From the view of model training, it is reported recently that a robust network can improve the performance of neural network modelling. Therefore, attempts of building a robust network to model the properties of maraging steels can be made.

\section{Conclusions}

Using data collected from literature, ANN modelling was carried out to simulate the correlation between alloy composition, processing parameters and properties of maraging steels. The input parameters in the model are the concentrations of 13 elements, C, Al, Co, Cr, Cu, Mn, Mo, $\mathrm{Nb}, \mathrm{Ni}, \mathrm{Si}, \mathrm{Ti}, \mathrm{V}$, and $\mathrm{W}$, degree of cold defor- mation prior to ageing, ageing temperature, and ageing time. Output parameters are eight mechanical properties and the Ms temperature. Different training parameters have been evaluated and the optimum model has been used for simulation. The calculations using the obtained models are in good agreement with experimental data. The simulation of the influence of combined $\mathrm{Co}$ and Mo alloying on Ms temperature, precipitation kinetics and mechanical properties has also been compared with experimental data and the results are very satisfactory. An explanation of the simulation results based on metallurgical mechanisms has been put forward. It is believed that the model can be used as a guide for practical optimisation of alloy composition and processing parameters for maraging steels, or low-carbon precipitation hardening steels, in order to achieve the desired combination of properties at different working temperatures. The model is the subject of ongoing development and improvement.

\section{Acknowledgements}

Prof. D.J. Cleland in the School of Civil Engineering at the Queen's University of Belfast was thanked for useful discussions. This work was carried out within the project of 'Computer Modelling of the Evolution of Microstructure during Processing of Maraging Steels' sponsored by the Engineering and Physical Sciences Research Council, UK, under grant no. GR/N08971. Dr. Sha's contribution to this work is sponsored under The Royal Academy of Engineering's Global Research Award Scheme.

\section{References}

[1] C.G. Bieber, Met. Progr. 78 (1960) 99.

[2] S. Floreen, R.F. Decker, in: R.F. Decker (Ed.), Source Book on Maraging Steels, ASM, Metals Park, OH, 1979, pp. 20-32.

[3] R.F. Decker, S. Floreen, in: R.K. Wilson (Ed.), Maraging Steels: Recent Developments and Applications, TMSAIME, Warrendale, PA, 1988, pp. 1-38.

[4] W. Sha, A. Cerezo, G.D.W. Smith, Phase chemistry and precipitation reactions in maraging steels: Part I. Intro- 
duction and study of Co-containing C-300 steel, Metall. Trans. A 24A (1993) 1221-1232.

[5] W. Sha, A. Cerezo, G.D.W. Smith, Phase chemistry and precipitation reactions in maraging steels: Part II. Co-free T-300 steel, Metall. Trans. A 24A (1993) 1233-1239.

[6] W. Sha, A. Cerezo, G.D.W. Smith, Phase chemistry and precipitation reactions in maraging steels: Part III. Model alloys, Metall. Trans. A 24A (1993) 1241-1249.

[7] W. Sha, A. Cerezo, G.D.W. Smith, Phase chemistry and precipitation reactions in maraging steels: Part IV. Discussion and conclusions, Metall. Trans. A 24A (1993) 12511255.

[8] S. Floreen, A.M. Bayer, in: R.K. Wilson (Ed.), Maraging Steels: Recent Developments and Applications, TMSAIME, Warrendale, PA, 1988, pp. 39-54.

[9] H.R. Shercliff, M.F. Ashby, A process model for age hardening of aluminium alloys-I: The model, Acta Metall. Mater. 38 (1990) 1789-1802.

[10] Z. Guo, W. Sha, E.A. Wilson, Modelling of precipitation kinetics and age hardening of $\mathrm{Fe}-12 \mathrm{Ni}-6 \mathrm{Mn}$ maraging type alloy, Mater. Sci. Technol. 18 (2002) 377-382.

[11] Z. Guo, W. Sha, Quantification of precipitation kinetics and age hardening of an $\mathrm{Fe}-12 \mathrm{Ni}-6 \mathrm{Mn}$ alloy during overaging, Mater. Sci. Technol. 18 (2002) 529-533.

[12] R.I. Ganguly, B.K. Dhindaw, Application of statistical design of experiments to strengthening behaviour of thermomechanically processed $\mathrm{Al}-\mathrm{Mg}-\mathrm{Si}-\mathrm{Cu}$ alloy, Met. Technol. (April) (1978) 114-117.

[13] R.F. Decker, J.T. Eash, A.J. Goldman, Trans. ASM 55 (1) (1962) 58.

[14] W.G. Vermeulen, P.J.V. Wolk, A.P. Weijer, S.V. Zwaag, Prediction of Jominy hardness profiles of steels using artificial neural networks, J. Mater. Eng. Perform. 5 (1) (1996) 57-63.

[15] H.K.D.H. Bhadeshia, Methodology of modelling and software, in: Modelling Phase Transformations in Steels, St. Catharine's College and Department of Materials Science and Metallurgy, Cambridge, 20-22 March, 1995.

[16] T. Cool, H.K.D.H. Bhadeshia, D.J.C. MacKay, The yield and ultimate tensile strength of steel welds, Mater. Sci. Eng. A 223A (1997) 186-200.

[17] H.K.D.H. Bhadeshia, D.J.C. MacKay, L.E. Svensson, Impact toughness of C-Mn steel arc welds-Bayesian neural network analysis, Mater. Sci. Technol. 11 (1995) 10461051.

[18] M. Li, J.A. Brooks, D.G. Atteridge, W.D. Porter, Thermophysical property measurements on low alloy high strength carbon steels, Scrip. Metall. Mater. 36 (1997) $1353-1359$.

[19] C. Dumortier, P. Lehert, P. Krupa, A. Charlier, Statistical modelling of mechanical properties of microalloyed steels by application of artificial neural networks, Mater. Sci. Forum 284-286 (1998) 393-400.

[20] L.X. Kong, P.D. Hodgson, D.C. Collinson, Modelling the effect of carbon content on hot strength of steels using a modified artificial neural network, ISIJ Int. 38 (10) (1998) $1121-1129$.
[21] Z. Guo, W. Sha, Modelling of beta transus temperature in titanium alloys using thermodynamic calculation and neural networks, in: I.V. Gorynin, S.S. Ushkov (Eds.), Proceedings of the 9th World Conference on Titanium, Saint Petersburg, Russia, June 7-11, 1999, Titanium 99: Science and Technology, vol. 1, Central Research Institute of Structural Materials, 2000, pp. 61-68.

[22] S. Malinov, W. Sha, Z. Guo, Application of artificial neural network for prediction of time-temperature-transformation diagrams in titanium alloys, Mater. Sci. Eng. A 283A (1-2) (2000) 1-10.

[23] S. Malinov, W. Sha, J.J. McKeown, Modelling the correlation between processing parameters and properties in titanium alloys using artificial neural network, Comput. Mater. Sci. 21 (2001) 375-394.

[24] P.J. Wolk, S. Zwaag, Workshop on artificial neural networks, Delft University of Technology, Laboratory of Materials Science, Rotterdamseweg 137, 2628 AL Delft, The Netherlands.

[25] M. Smith, Neural Networks for Statistical Modelling, Van Nostrand Reinhold, New York, 1993.

[26] K. Hornik, M. Stinchcombe, H. White, Multilayer feedforward networks are universal approximators, Neural Networks 2 (5) (1989) 359-366.

[27] R.F. Decker (Ed.), Source Book on Maraging Steels, ASM, Metals Park, OH, 1979.

[28] R.K. Wilson (Ed.), Maraging Steels: Recent Developments and Applications, TMS-AIME, Warrendale, PA, 1988.

[29] B. Pollard, Selection of Wrought Precipitation-Hardening Stainless Steels, in: ASM Handbook, vol. 6, ASM, Materials Park, OH, 1993, pp. 482-494.

[30] E.P. Sadowski, Development of a stainless maraging steel, Met. Eng. Quart. 2 (2) (1974) 47-55.

[31] H. Suto, Z.D. Yin, Composition of $3.5 \mathrm{GPa}$ grade maraging steels and the thermo-mechanical treatments, J. Jpn. Inst. Met. 45 (6) (1981) 641-647.

[32] M.D. Perkas, Metall. Term. Obrab. Met. 5 (1985) 23-33.

[33] G.F. Vander Voort (Ed.), Altas of Time-Temperature Diagrams for Irons and Steels, ASM International, Materials Park, OH, 1991.

[34] C.S. Carter, The effect of heat treatment on the fracture toughness and subcritical crack growth characteristics of a 350-grade maraging steel, Metall. Trans. 1 (1970) 15511559.

[35] G.J. Spaeder, Impact transition behaviour of high-purity 18Ni maraging steel, Metall. Trans. 1 (1970) 2011-2014.

[36] A. Magnee, J.M. Drapier, J. Dumont, D. Coutsourdis, L. Habraken, Cobalt-Containing High-Strength Steels, Centre D'Information Du Cobalt, Brussels, 1974, p. 72.

[37] Eagle International Software Inc. Available from <http:// my.metalinfo.com/mm_utilities/hardnesschart.cfm, 2000>.

[38] The Math Works, Inc. product, Neural Network Toolbox Version 3 for MatLab, pp. 5_51-5_58, 6_1-6_20.

[39] N. Cristianini, J. Shawe-Taylor, An Introduction to Support Vector Machines and Other Kernel-based Learning Methods, Cambridge University Press, Cambridge, 2000 . 
[40] Y.H. Hu, J.N. Hwang (Eds.), Handbook of Neural Network Signal Processing, CRC Press, Boca Raton, FL, 2002.

[41] C.M. Hammond, The development of maraging stainless steels containing cobalt, Cobalt (25) (1964) 195202.

[42] P.G. Shewmon, Transformations in Metals, McGraw-Hill, London, 1969, p. 340.

[43] K.W. Andrews, J. Iron Steel Inst. 203 (1965) 271.

[44] D.R. Squires, F.G. Wilson, E.A. Wilson, The Influence of $\mathrm{Mo}$ and $\mathrm{Co}$ on the embrittlement of an $\mathrm{Fe}-\mathrm{Ni}-\mathrm{Mn}$ alloy, Metall. Trans. 5 (1974) 2569-2578.

[45] R.B.G. Yeo, Trans. TMS-AIME 227 (1963) 884.

[46] G.W. Tuffnell, R.L. Cairns, 18\% Nickel 350 maraging steel, Trans. ASM 61 (1968) 798.

[47] K. Hosomi, H. Morimoto, Y. Ashida, Effect of Co, Mo and $\mathrm{Ti}$ contents on mechanical-properties of $\mathrm{Ni}-18$ ma- raging steels, Tetsu To Hagane-J. Iron Steel Inst. Jpn. 74 (10) (1988) 2025-2032.

[48] S. Floreen, G.R. Speich, in: R.F. Decker (Ed.), Source Book on Maraging Steels, ASM, Metals Park, OH, 1979, pp. 326-338.

[49] K. Rohrbach, M. Schmidt, Maraging Steels, in: Metals Handbook, vol. 1, 10th ed., ASM, Materials Park, OH, 1990, p. 796.

[50] P. Liu, A.H. Stigenberg, J.O. Nilsson, Isothermally formed quasicrystalline precipitates used for strengthening in a new maraging stainless steel, Scrip. Metall. Mater. 31 (1994) 249-254.

[51] Data sheet-precision wire products, AB Sandvik Steel, Wire Division, SE-811 81 Sandviken, Sweden, 2001.

[52] K. Stiller, M. Hattestrand, F. Danoix, Precipitation in $9 \mathrm{Ni}-12 \mathrm{Cr}-2 \mathrm{Cu}$ maraging steels, Acta Mater. 46 (1998) 6063-6073. 